\title{
Reply to 'Evidence that neutrophils do not promote Echis carinatus venom-induced tissue destruction'
}

\author{
Kempaiah Kemparaju ${ }^{1}$, Kesturu S. Girish ${ }^{1,2}$ \& Gajanan D. Katkar ${ }^{1,3}$
}

Prof. Reber and his team for providing further insight into Echis carinatus venom-induced tissue necrosis in their correspondence ${ }^{1}$ regarding our Nature Communications article ${ }^{2}$. We are glad that our major findings such as reduction in E. carinatus venominduced tail injury after DNase I treatment, increased the mortality of mice when co-injected with E. carinatus venom and DNase I, function of venom DNase in toxicity, and the application of the newly developed mouse tail model to study sustained tissue necrosis have been ratified. These effects are due to the accumulation of extracellular DNA and its clearance by the DNase I treatment at the venom injected site. However, using a variety of neutropenic mouse models, the authors claim that neutrophils or neutrophils extracellular traps (NETs) do not contribute to E. carinatus sochureki, E. carinatus multisquamatus, or E. carinatus pyramidum venom-induced tissue necrosis, but the extracellular traps (ETs) derived from resident and other necrotic cells do contribute. Unlike our published article, they do not test E. carinatus carinatus (Indian saw-scaled viper) venom.

We believe that the differences in results are due to dose and species-dependent variation of the venoms tested. Snake venoms are highly complex mixtures, predominantly of enzymatic and non-enzymatic protein and peptide toxins that vary in lethal potency and pharmacological properties. Variability has been detected at various levels including inter-genus, inter-species, inter-subspecies, and within species and sub-species due to geographical or seasonal distribution, age, and diet ${ }^{3-6}$. Venom variability is thereby an intense area of research with serious implications for successful application of anti-venom therapy. In a previous study, we showed substantial differences in hemorrhage-inducing activity between $E$. carinatus carinatus and E. carinatus sochureki ${ }^{7}$, providing direct evidence of venom variability between E. carinatus sub-species. Furthermore, we believe it is probable that E. carinatus sochureki, E. carinatus multisquamatus, and E. carinatus pyramidum venoms used by the authors may vary among themselves.

We are glad that the authors acknowledge venom variability and that E. carinatus carinatus venom and the venoms that they have studied are different, and that this distinction might be responsible for the differences between the studies. In our study, both in vitro and in vivo data (assays of several markers of
NETosis) demonstrate NETosis ${ }^{2}$. In contrast, the authors defend their finding using neutropenic mouse models injecting with a high dose of venom, but without defining the molecular mechanisms.

We believe that aside from venom variability, the differences between our studies may also result from a varied dose of venom injected. The authors have injected $3 \mathrm{mg}$ venom $/ \mathrm{kg}$ body weight in $25 \mu \mathrm{l}$, as against $1 \mathrm{mg}$ venom/ $\mathrm{kg}$ body weight in $50 \mu \mathrm{l}$ injected in our study. Pertaining to the dose injected, although it appears that there exists a systemic difference of 1: 3 dose between the studies, actually, it is the difference between $1 \mathrm{mg}$ in $50 \mu \mathrm{lvs} .3 \mathrm{mg}$ in $25 \mu \mathrm{l}$ at the injection site (mouse tail). Thus, it clearly suggests that there is a 1:6-fold increase in venom concentration at the injection site and that this might non-specifically lyse the resident and the other cells, including the subcellular membranes.

Regarding the criticism of our use of cyclophosphamide to achieve neutropenia, we agree that cyclophosphamide is a pleiotropic drug and affects various blood cells, including lymphocytes, monocytes, basophils, and eosinophils, as well as hematopoiesis itself. Although several studies have used cyclophosphamide to induce neutropenia ${ }^{8,9}$, we resorted to the use of cyclophosphamide owing to a lack of access to other models of neutropenia.

Received: 25 October 2017 Accepted: 3 May 2018

Published online: 13 June 2018

\section{References}

1. Stackowicz, J. et al. Evidence that neutrophils do not promote Echis carinatusvenom-induced tissue destruction. Nat. Commun. https://doi.org/10.1038/s41467-018-04688-6 (2018).

2. Katkar, G. D. et al. NETosis and lack of DNase activity are key factors in Echis carinatus venom-induced tissue destruction. Nat. Commun. 7, 11361 (2016).

3. Barlow, A., Pook, C. E., Harrison, R. A. \& Wüster, W. Coevolution of diet and prey-specific venom activity supports the role of selection in snake venom evolution. Proc. Biol. Sci. 276, 2443-2449 (2009).

4. Shashidharamurthy, R., Jagadeesha, D. K., Girish, K. S. \& Kemparaju, K. Variations in biochemical and pharmacological properties of Indian cobra (Naja naja naja) venom due to geographical distribution. Mol. Cell. Biochem. 229, 93-101 (2002).

\footnotetext{
${ }^{1}$ Department of Studies in Biochemistry, University of Mysore, Manasagangothri, Mysuru 570006, India. ${ }^{2}$ Department of Studies and Research in Biochemistry, Tumkur University, Tumakuru 572103, India. ${ }^{3}$ Present address: Institute of Biomedical Sciences, Academia Sinica, Taipei 115, Taiwan. Correspondence and requests for materials should be addressed to K.K. (email: kemparajuom@gmail.com) or to K.S.G. (email: ksgbaboo@gmail.com)
} 
5. Chippaux, J. P., Williams, V. \& White, J. Snake venom variability: methods of study, results and interpretations. Toxicon 29, 1279-1303 (1991).

6. Casewell, N. R., Harrison, R. A., Wuster, W. \& Wagstaff, S. C. Comparative venom gland transcriptome surveys of the saw-scaled vipers (Viperidae: Echis) reveal substantial intra-family gene diversity and novel venom transcripts. BMC Genomics 10, 564 (2009).

7. Sunitha, K. et al. Neutralization of haemorrhagic activity of viper venoms by 1-(3-dimethylaminopropyl)-1-(4-fluorophenyl)-3-oxo-1,3dihydroisobenzofuran-5-carbonitrile. Basic Clin. Pharmacol. Toxicol. 109, 292-299 (2011).

8. Zuluaga, A. F. et al. Neutropenia induced in outbred mice by a simplified lowdose cyclophosphamide regimen: characterization and applicability to diverse experimental models of infectious diseases. BMC Infect. Dis. 6, 55 (2006).

9. Dale, D. C., Alling, D. W. \& Wolff, S. M. Cyclic hematopoiesis: the mechanism of cyclic neutropenia in grey collie dogs. J. Clin. Invest. 51, 2197-2204 (1972).

\section{Acknowledgements}

K.K. acknowledges the funding from the DST-SERB (EEQ/2016/000193), UGC-SAP (F314/2012 SAP-II), and VGST [VGST/K-FIST (2010-11)/GRD-36/2013-14].

\section{Author contributions}

K.K., K.S.G., and G.D.K. conceived the idea, designed the research, discussed the data, and wrote the paper.

\section{Additional information}

Competing interests: The authors declare no competing interests.

Reprints and permission information is available online at http://npg.nature.com/ reprintsandpermissions/

Publisher's note: Springer Nature remains neutral with regard to jurisdictional claims in published maps and institutional affiliations.

\section{(c) (1)}

Open Access This article is licensed under a Creative Commons Attribution 4.0 International License, which permits use, sharing, adaptation, distribution and reproduction in any medium or format, as long as you give appropriate credit to the original author(s) and the source, provide a link to the Creative Commons license, and indicate if changes were made. The images or other third party material in this article are included in the article's Creative Commons license, unless indicated otherwise in a credit line to the material. If material is not included in the article's Creative Commons license and your intended use is not permitted by statutory regulation or exceeds the permitted use, you will need to obtain permission directly from the copyright holder. To view a copy of this license, visit http://creativecommons.org/ licenses/by/4.0/.

(C) The Author(s) 2018 